\title{
Big tobacco using Trojan horse tactics to exploit Indigenous peoples
}

\author{
Andrew Waa (1) 1,2 Raglan Maddox, ${ }^{3,4}$ Patricia Nez Henderson ${ }^{5,6}$
}

${ }^{1}$ Public Health, University of Otago, Wellington, New Zealand ${ }^{2}$ Ngati Hine/Ngapuhi

${ }^{3}$ Aboriginal and Torres Strait Islander Health Program, National Centre for Epidemiology and Public Health, Australian National University, Canberra, Australian Capital Territory, Australia

${ }^{4}$ Modewa Clan

${ }^{5}$ Black Hills Center for American Indian Health, Rapid City, South Dakota, USA

${ }^{6}$ Navajo Nation (Diné)

\section{Correspondence to} Andrew Waa, Public Health, University of Otago Wellington, Wellington 6242, New Zealand: Andrew.waa@otago.ac.nz

Published Online First 30 May 2020

\section{Linked}

- http://dx.doi.org/10.1136/ tobaccocontrol-2020-055669

Check for updates

(C) Author(s) (or their employer(s)) 2020. No commercial re-use. See rights and permissions. Published by BMJ.

To cite: Waa A, Maddox R, Nez Henderson P. Tob Control 2020;29:e132-e133.
The tobacco industry has a long history of exploiting Indigenous peoples and their culture. During the 1980s, tobacco company WD \& HO Wills ran racist advertising in Australia carrying the slogan 'Get your own black'. In the late 1990s, Winfield advertisements depicted an Aboriginal man playing a didgeridoo with the slogan 'Australians' answer to the peace pipe'. ${ }^{12}$ More recently, Philip Morris International (PMI) has sold cigarettes in Israel labelled 'Māori Mix'3 and in the USA, R.J. Reynolds continues to market Natural American Spirit using Native American imagery. ${ }^{4}$ Thus, tobacco industry exploitation of Indigenous peoples continues.

Thompson et al draw our attention to how the tobacco industry is now focusing on Indigenous peoples to promote their Alternative Nicotine Delivery Systems (ANDS). They discuss how Rothmans, Benson and Hedges targeted Indigenous health leaders, ostensibly to promote their vision of a smoke-free Canada but in a way that instead promoted switching to (their) ANDS products. By adopting a tone of remorse and packaging their marketing message in the language of reconciliation, the tobacco company's products appear almost as an offering to make amends for their past misdeeds.

Similar tactics promoting ANDS have been employed elsewhere. In the USA, tribal communities were subjected to a concerted effort by Altria to get them to engage with Juul. ${ }^{67}$ Meanwhile in Australia, PMI has attempted to enlist Aboriginal and Torres Strait Islander organisations and leaders to promote vaping. ${ }^{67}$ Similar efforts have been made by PMI in New Zealand by targeting Māori communities to promote IQOS. ${ }^{8}$ The PMIfunded Foundation for a Smoke-free World has also targeted Indigenous communities with funding to promote activities consistent with industry 'harm reduction' approaches, triggering concerns from Indigenous researchers and the media. ${ }^{9} 10$

Smoking rates are declining internationally, ${ }^{11}$ but over the past decade, there has been a huge rise in popularity of ANDS. Switching from selling tobacco products to ANDS could be an easy option for tobacco companies. Such a move might shore up declining profit margins, while building their social responsibility profiles through being associated with potentially less harmful products. This approach seems to be supported by industry rhetoric, particularly from PMI and its associates, about working towards a smoke-free world, but one that creates space for their ANDS. Others have debunked these claims, noting the industry still aggressively promotes smoking in low and middle-income countries and has not set definitive timelines to stop selling and promoting tobacco. ${ }^{12}$ They have also noted that in attempting to carve out a share in the ANDS market, the tobacco industry has acted irresponsibly by recruiting non-nicotine users, including young people. ${ }^{13}$

Do the tobacco industry activities and motives matter if there is potential for significant health gain among Indigenous peoples? We believe they do, for at least three reasons. First, Thompson et al highlight the tobacco industry's desire for Indigenous peoples to endorse and use their ANDS products. But Indigenous youth are invariably more likely than non-indigenous youth to be exposed to risk factors associated with substance abuse. ${ }^{14}$ This makes them particularly at risk of taking up ANDS, even if they never smoked. While some theorise that taking up ANDS could prevent young people from becoming smokers, ${ }^{15} 16$ such a stance is fatalistic, ignores declining rates of youth tobacco use and is inconsistent with protecting the well-being of our young peoples.

Second, we are concerned about the tobacco industry targeting Indigenous communities and undermining Indigenous self-determination, particularly our ability to make decisions unfettered by external corporate agendas. Indigenous-led decision-making is central to resisting the ongoing impacts of colonisation. By attempting to recruit Indigenous peoples to their cause, the tobacco industry is undermining our self-determination. ${ }^{17}$

Finally, the actions of the tobacco industry demonstrate they are prepared to continue to exploit Indigenous peoples, this time through Trojan horse tactics to influence policy. In a 2014 corporate affairs presentation, ${ }^{18}$ PMI highlighted its desire to promote its then new IQOS product. Tactics planned for achieving this included playing the 'political game' to legitimise their products and finding 'allies that cannot be ignored'. With much debate about how vaping and heat-not-burn products should be regulated, Indigenous peoples could offer the useful political 'ally' for the tobacco industry that is hard to ignore. This could explain PMI's interest in Māori leaders and communities in the lead up to the introduction of draft legislation to regulate ANDS. ${ }^{78}$

To counter tobacco industry tactics promoting ANDS and seeking to take advantage of Indigenous peoples, we ask for Indigenous peoples, governments and others to identify and expose the tobacco industry's attempts to enlist Indigenous communities. Our work should recognise the United Nations Declaration on the Rights of Indigenous Peoples ${ }^{19}$ 
and Indigenous clauses within the WHO Framework Convention on Tobacco Control. ${ }^{20}$ We call all governments and NGOs to protect and enable Indigenous leadership and champions so that we are protected from tobacco industry interests.

Contributors All authors discussed and agreed the content of the manuscript. AW led the development of the editorial. RM and PNH added perspectives and information from their respective countries and reviewed draft manuscripts.

Funding The authors have not declared a specific grant for this research from any funding agency in the public, commercial or not-for-profit sectors.

Competing interests No, there are no competing interests.

Patient consent for publication Not required.

Provenance and peer review Commissioned; internally peer reviewed.

ORCID iD

Andrew Waa http://orcid.org/0000-0002-8078-0283

\section{REFERENCES}

1 van der Sterren A, Greenhalgh E, Knoche D. The tobacco industry and Indigenous communities. In: Scollo M, Winstanley M, eds. Tobacco in Australia: facts and issues. Melbourne: Cancer Council, 2016.

2 Thomas DP, Bond L. The tobacco industry and Aboriginal and Torres Strait Islander people. Med J Aust 2012;197:24-6.

3 Herald NZ. Māori mix cigarettes in Israel ignites row. New Zealand: New Zealand Herald, 2005.

4 D'Silva J, O'Gara E, Villaluz NT. Tobacco industry misappropriation of American Indian culture and traditional tobacco. Tob Control 2018;27:e57-64.

5 Thompson S, Smith J, Lee K, et al. Industry sponsored harm reduction conference courts Indigenous peoples in Canada. Tob Control 2020;29:e129-30.
6 Ducharme J. It's Insidious': How Juul Pitched E-Cigs to Native American Tribes. Time 2020

7 Hutcheon S, Bogle A. Smoke and mirrors: the nanny state critics behind the vape debate. $A B C$ News 2019.

8 Espiner G. Big tobacco targeting Māori with e-cigarettes. RNZ 2019

9 Waa A, Robson B, Gifford H, et al. Foundation for a smoke-free world and healthy Indigenous futures: an oxymoron? Tob Control 2020;29:237-40.

10 Aziani A. Request for an interview on the drivers of smoking cessation in Australia. Universit Cattolica del Sacro Cuore (Milan, Italy) working as consultants at BOTEC analysis. funded by the foundation for a smoke free world 2020.

11 World Health Organization. WHO global report on trends in prevalence of tobacco smoking 2000-2025. World Health Organization, 2018.

12 Davies M, Stockton B, Chapman M, et al. The 'Unsmoke' screen: the truth behind PMI's cigarette-free future. The Bureau of Investigative Journalism 2020.

13 Robertson L, Hoek J, Gilmore A, et al. Regulating vaping and new nicotine products: Are tobacco companies' goals aligned with public health objectives? Public Health Expert. New Zealand: Otago, 2020

14 Snijder M, Stapinski L, Lees B, et al. Preventing substance use among Indigenous adolescents in the USA, Canada, Australia and New Zealand: a systematic review of the literature. Prev Sci 2020;21:65-85.

15 Erku DA, Morphett K, Steadman KJ, et al. Policy debates regarding nicotine vaping products in Australia: a qualitative analysis of submissions to a government inquiry from health and medical organisations. Int J Environ Res Public Health 2019;16:4555.

16 Mendelsohn C. Smokefree environments and regulated products (Vaping) Amendment bill hearing of evidence. meeting NSC, 2020.

17 American Nonsmokers' Rights Foundation. Tribal Sovereignty and e-cigarette companies 2019

18 Kalra A, Bansal P, Wilson D, et al. Inside Philip Morris' campaign to subvert the global anti-smoking treaty 2017.

19 United Nations. United nations Declaration on the rights of Indigenous peoples 2008

20 World Health Organization. Framework convention on tobacco control. Geneva: WHO Document Production Services, 2003: 44. 